\title{
A escritora Hilda Hilst, o editor Massao Ohno, as artes literárias e o fazer-memória nos fluxos digitais
}

Débora Regina Bacega ${ }^{1}$

\section{Considerações iniciais}

Hilda Hilst (1930-2004) é autora de mais de 40 obras literárias, parte delas lançada no mercado editorial pelo selo independente que traz o nome do artista gráfico Massao Ohno (1936-2010), como: Trovas de muito amor para um amado senhor ${ }^{2}$ (1961), Sete cantos do poeta para o anjo 3 (1962), Júbilo, memória, noviciado da paixão (1974), Da Morte. Odes mínimas ${ }^{5}$ (1980), Cantares de perda e predileção ${ }^{6}$ (1980), Sobre a tua grande face ${ }^{7}$ (1986), Amavisse $e^{8}$ (1989), Bufólicas ${ }^{9}$ (1992), A obscena senhora $D^{10}$ (1982), O caderno rosa de Lori Lamby ${ }^{11}$ (1990), Do amor ${ }^{12}$ (1999). Graduado em Odontologia, Ohno inicia a sua carreira como designer gráfico na década de 1950 com a impressão de apostilas para cursos pré-vestibulares. A convivência com a atmosfera cultural do centro da cidade de São Paulo, como a Biblioteca Mário de Andrade (BMA), intensifica o seu interesse pela arte literária, como podemos observar em suas palavras ao Projeto Memória Oral da instituição, em abril de 2009: “a Biblioteca está na raiz disso tudo" ${ }^{13}$. Paulatinamente, o selo independente Massao Ohno Editor se torna sinônimo de obras de poetas brasileiros até então desconhecidos como Cláudio Willer, Renata Pallottini, Olga Savary, Eduardo Alves da Costa, Roberto Piva, Celso Luís Paulini, Paulo del Greco, Carlos Felipe Moisés e Hilda Hilst, entre outros.

Observamos que a proximidade entre Hilst e Ohno permite a semeadura de projetos gráficos que, em certa medida, revelavam a poética hilstiana e a sensibilidade artística do designer. Por outro lado, a relação duradoura também reverbera a falta de distribuição dos títulos hilstianos no mercado editorial, como podemos observar no texto do professor e crítico literário Alcir Pécora sobre o lançamento do livro Massao Ohno, Editor $(2020)^{14}$, cujo trecho transcrevemos:

\footnotetext{
${ }^{1}$ Doutoranda e mestre em Comunicação e Práticas de Consumo pelo PPGCOM ESPM/SP. Bolsista CAPES PROSUP. Integrante do Mnemon (Grupo de Pesquisa em Memória, comunicação e consumo), certificado CNPq/ ESPM. E-mail: deborabacega@gmail.com

${ }^{2}$ HILST, HILDA. Trovas de muito amor para um amado senhor. São Paulo: Massao Ohno, 1961.

${ }^{3}$ Hilst, HILDA. Sete cantos do poeta para o anjo. São Paulo: Massao Ohno, 1962.

${ }^{4}$ HILST, HILDA. Júbilo, memória, noviciado da paixão. São Paulo: Massao Ohno, 1974.

${ }^{5}$ Hilst, Hilda. Da Morte. Odes mínimas. São Paulo: Massao Ohno, Roswitha Kempf, 1980.

${ }^{6}$ Hilst, HILdA. Cantares de perda e predileção. São Paulo: Massao Ohno/M. Lídia Pires e Albuquerque Editores,1980.

${ }^{7}$ Hilst, HiLdA. Sobre a tua grande face. São Paulo: Massao Ohno, 1986.

${ }^{8}$ Hilst, Hilda. Amavisse. São Paulo: Massao Ohno, 1989.

${ }^{9}$ Hilst, Hilda Bufólicas. São Paulo: Massao Ohno, 1992.

${ }^{10}$ Hilst, HILdA A obscena senhora D. São Paulo: Massao Ohno, 1982.

${ }^{11}$ HiLST, HiLdA. O caderno rosa de Lori Lamby. São Paulo: Massao Ohno, 1990.

${ }^{12}$ Hilst, Hilda. Do amor. São Paulo. Massao Ohno, 1999.

13 Biblioteca Mario de Andrade. Projeto Memória Oral. 3. Abril. 2009. São Paulo/SP. Disponível em: https://www.prefeitura.sp.gov.br/cidade/upload/Depoimento_Massao_Ohno_1276539751.pdf Acesso em: 5 jul. 2021.

${ }^{14}$ SILVA, JosÉ. ARMANDO. P. Massao Ohno, editor. São Paulo: Ateliê Editorial, 2020.
} 
(...) toda vez que a própria Hilda Hilst terminava um livro, logo surgia o nome de Ohno para editá-lo, ela invariavelmente se queixava, a despeito da amizade genuína, de que ele, após fazer os livros, escondia-os debaixo do próprio colchão. Dizia isso sempre de maneira hilária, encenando o desdém de Ohno com a distribuição dos livros que editava magnificamente De fato, essa [era a] maneira de Ohno conceber a edição de livros, inteiramente dedicada à criação gráfica, e esquecido da distribuição e de outros aspectos [comerciais] do negócio $(. . .)^{15}$.

O editor, por sua vez, se justificava, dizendo que as tiragens de mil exemplares do seu selo editorial tinham como destino as outras editoras, e não os leitores. Em entrevista ao jornalista e pesquisador Gutemberg Medeiros, Ohno revela: "não sou editor, sou designer gráfico (...) Os editores dificilmente publicam poesia, alegam dar prejuízo. Então eu publico para o poeta apresentar a sua produção impressa nas editoras. (...) melhor mostrar a obra em livro do que em cópias datilografadas. Não edito para o leitor final, mas para editores." ${ }^{16}$ No entanto, foi Ohno quem mais publicou Hilst, pois "ela sabia o que viria: um grande livro, um elogio à sua poesia." ${ }^{17}$ Por outro lado, em entrevistas à imprensa ${ }^{18}$, a poeta confessava seu ressentimento pela ausência de leitores, apesar de ter sido traduzida em Portugal, Itália, França, Alemanha, Estados Unidos, Canadá, Argentina. ${ }^{19}$ Ainda na ocasião do Projeto Memória Oral da BMA, cinco anos após o falecimento da escritora, Ohno declara: “a [morte de] Hilda [Hilst] foi (...) uma perda lamentável. Nós éramos muito amigos e trocávamos ideias sobre tudo e todos" 20 .

A partir desses apontamentos, pretendemos apresentar neste artigo as práticas mnemônicas transversais compreendidas nos acervos biobibliográficos hilstianos que refletem tanto o conjunto literário produzido pela escritora quanto a dimensão biográfica de sua trajetória materializada em testemunhos, documentos, fotografias, objetos ou espaços. Nessa toada, buscamos responder à seguinte pergunta: como essas práticas podem corroborar a perenidade da relação entre a escritora e o editor Massao Ohno nos fluxos digitais? Para tanto, apresentamos as contribuições de pesquisadores das temáticas dos aspectos socioculturais e arquivísticos da memória. Neste estudo de caso, observamos os conteúdos on-line publicados com as hashtags \#hildahilst e \#massaoohno nas seguintes plataformas: o blog do Instituto Hilda Hilst (IHH), a página @instituto_hilda_hilst no Instagram e o canal @CuradoriaHilst no YouTube. Esperamos demonstrar como essas práticas podem contribuir com o fazer-memória de Hilst, de Ohno e das artes literárias na ambiência digital.

\footnotetext{
${ }^{15}$ PÉCORA, AlCIR. "Livro sobre Massao Ohno teve pesquisa criteriosa mas falta biografia”. Folha S. Paulo on-line. Disponível em: https://www1.folha.uol.com.br/ilustrada/2020/04/livro-sobre-massao-ohno-teve-pesquisa-criteriosa-mas-faltabiografia.shtml?origin=folha Acesso em: 15 jun. 2021.

16 Medeiros, Gutemberg. “Massao Ohno, Hilda Hilst e os três triplos”. Jornal da USP on-line. Disponível em: https://jornal.usp.br/artigos/massao-ohno-hilda-hilst-e-tres-triplos/ Acesso em: 15 jun. 2021.

17 Instituto Hilda Hilst. Blog. "Série Massao Ohno: Encontro de Poetas". Disponível em: http://www.hildahilst.com.br/blog/serie-massao-ohno-encontro-de-poetas Acesso em: 1 jul. 2021.

${ }^{18}$ DinIZ, CRISTIANO. (org.). Fico besta quando me entendem: entrevistas com Hilda Hilst. Biblioteca Azul. São Paulo: Editora Globo, 2013.

${ }^{19}$ InSTITUTO HILDA HILST. Site. Disponível em: http://www.hildahilst.com.br/hilda. Acesso em: abr. 2021.

20 Biblioteca Mario De Andrade. Projeto Memória Oral. 3. Abril. 2009. São Paulo/SP. Disponível em: https://www.prefeitura.sp.gov.br/cidade/upload/Depoimento_Massao_Ohno_1276539751.pdf Acesso em: 3 jul. 2021.
} 


\section{Os acervos biobibliográficos e os rastros digitais}

Com o intuito de preservar tanto o acervo biobibliográfico ${ }^{21}$ da poeta quanto a Casa do Sol, local onde a escritora viveu até a sua morte, surge, em 2005, o Instituto Hilda Hilst (IHH). Daniel Fuentes, presidente do IHH e herdeiro dos direitos autorais da escritora, afirma em texto de sua autoria publicado na Revista Cult, em 2018, que: "o maior desafio do IHH [é], conseguir aliar crescimento exponencial do público leitor de Hilda com a preservação de seu legado mais amplo materializado na Casa do Sol”22. Nesse sentido, nos últimos anos, percebemos que o IHH vem intensificando a divulgação do acervo biobibliográfico de Hilst no site www.hildahilst.com.br, assim como, nas redes sociais Facebook e Instagram. Recentemente, por conta do contexto pandêmico, o IHH lançou o canal Curadoria Hilst no YouTube com programação semanal, como ilustra a figura 1 .

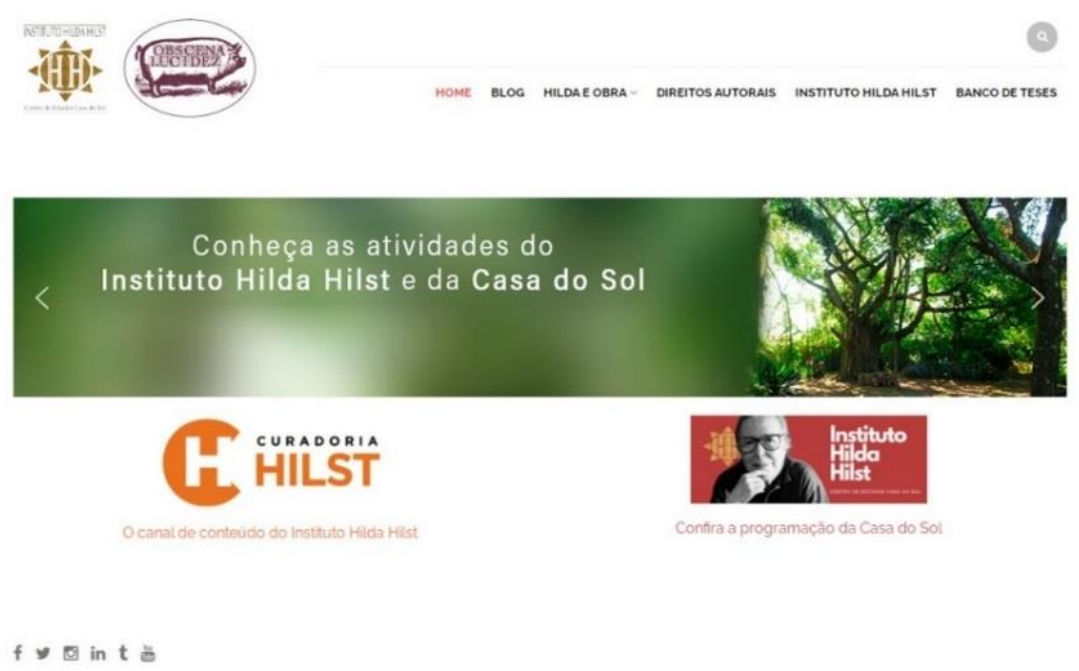

Figura 1 - Tela capturada do site do Instituto Hilda Hilst (IHH)

Fonte: http://www.hildahilst.com.br/

Já em relação ao editor independente, identificamos a criação do Acervo Massao Ohno na Biblioteca Mario de Andrade em 2010, resultado da doação de 30 caixas por parte de familiares e amigos, como podemos observar em texto divulgado no site da instituição, onde lemos: "por sugestão de amigos e admiradores de Massao Ohno, a Biblioteca Mário de Andrade assumiu a iniciativa de formar a coleção Massao Ohno, que será colocada à disposição, para consulta e pesquisa, de interessados na história literária e das artes gráficas no Brasil”23.

Por outro lado, nessas caixas, encontram-se "muitos títulos originais e raros de Hilda Hilst" ${ }^{24}$, a exemplo de Bufólicas ${ }^{25}$, como podemos observar no conteúdo publicado pelo Instituto Hilda Hilst em sua página no Instagram em 2015, cujo texto transcrevemos: "Desde 2010, a @bibliotecamariodeandrade está construindo o acervo de Massao Ohno, e muitos títulos

\footnotetext{
${ }^{21}$ Nota-se que parte do acervo de Hilda Hilst está disponível para consulta no Centro de Documentação Cultural Alexandre Eulálio da Universidade Estadual de Campinas (Cedae-Unicamp) Campinas/São Paulo.

${ }^{22}$ FuENTES, DANIEL. “A gestão de um legado”. Cult. São Paulo: Editora Bregantini, n. 233, p. 38-41, abr. 2018.

${ }^{23}$ Biblioteca Mario de Andrade. Site. Acervo Massao Ohno. Disponível em: https://www.prefeitura.sp.gov.br/cidade/secretarias/cultura/bma/projetos/?p=8233 Acesso em: julho 2021.

${ }^{24}$ Disponível em: https://www.instagram.com/p/9eK--VpNZU/ Acesso em: julho 2021.

${ }^{25}$ Op. cit.
} 
originais e raros de Hilda Hilst estão lá! (...)”26. Destacamos também o uso das hashtags \#hildahilst, \#massaoohno, \#literatura, \#mariodeandrade, \#biblioteca e \#livros nesta publicação como ilustra a figura 2.

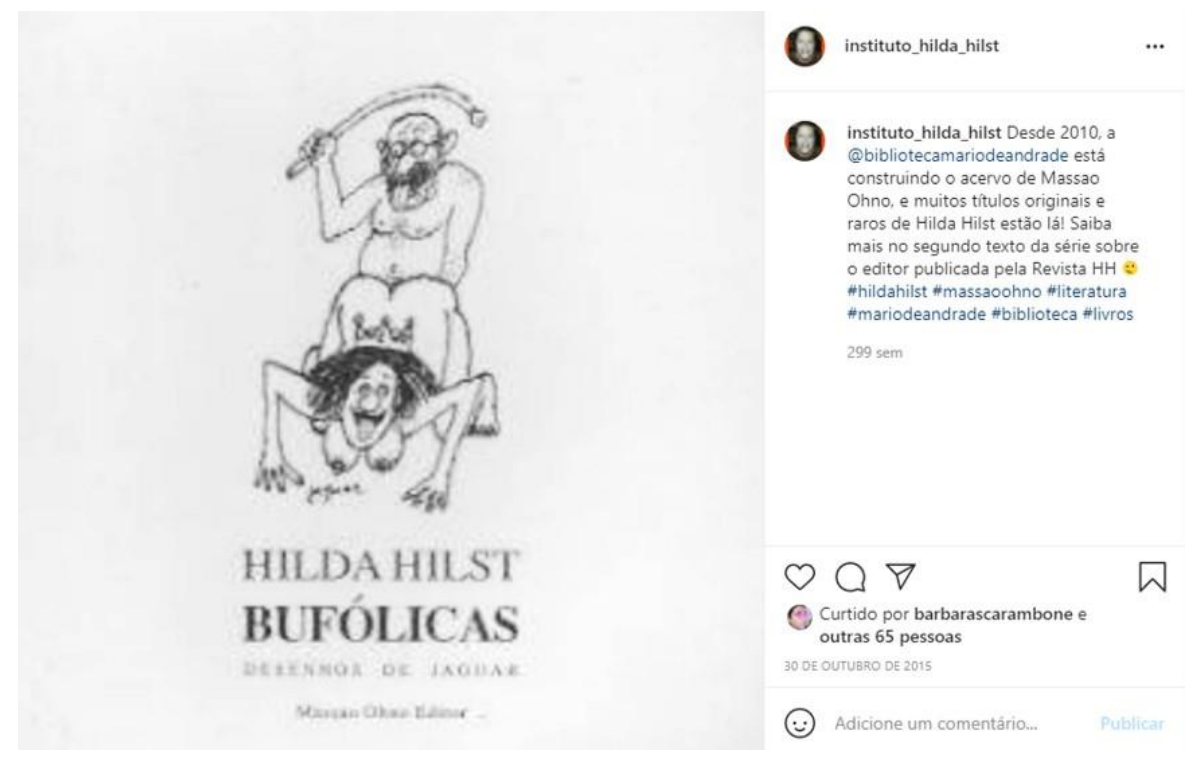

Figura 2 - Tela capturada do Instagram do IHH sobre o acervo de Massao Ohno na BMA e as obras hilstianas Fonte: @instituto_hilda_hilst ${ }^{27}$

Identificamos que o "Legado na biblioteca Mário de Andrade" também é tema da Série Massao Ohno, publicada no blog do Instituto Hilda Hilst ${ }^{28}$. Também fazem parte dessa coletânea os textos: "Encontro de poetas", "Entrevista com Claudio Willer" e "O samurai das sombras", sendo este último sobre o filme Massao Ohno - Poesia Presente ${ }^{29}$, da diretora Paola Prestes. Exibida na 39a Mostra Internacional de Cinema de São Paulo (2015), a produção fílmica aborda a trajetória de Massao Ohno, ressaltando a sua relevância para as artes editoriais e gráficas.

Sobre o documentário, nota-se que o IHH publica uma mensagem em sua página no Instagram. Nela, ao lado da fotografia em preto e branco de Ohno e Hilda, lemos o texto: "hoje a Revista HH inicia uma série de matérias sobre Massao Ohno, grande editor das obras de Hilda Hilst. O primeiro texto fala do documentário 'Massao Ohno - Poesia Presente', que estreia amanhã na @mostrasp"30. Mais uma vez, há o uso de hashtags \#hildahilst, \#massaoohno, \#mostra, \#cinema, \#literatura e \#arte, como podemos ver na figura 3.

\footnotetext{
${ }^{26}$ Disponível em: https://www.instagram.com/p/9eK--VpNZU/ Acesso em: julho 2021.

${ }^{27}$ Disponível em: https://www.instagram.com/p/9eK--VpNZU/ Acesso em: jul. 2021.

${ }^{28}$ InstituTo Hilda Hilst. Blog. “Série Massao Ohno: Legado na Biblioteca Mário de Andrade”. Disponível em: http://www.hildahilst.com.br/blog/serie-massao-ohno-legado-na-biblioteca-mario-de-andrade Acesso em: jul. 2021.

${ }^{29}$ Prestes, Paola. Massao Ohno - Poesia Presente. Documentário, 90 min, Brasil, 2015.

${ }^{30}$ Disponível em: https://www.instagram.com/p/9J4sJWJNc0/ Acesso em: jul. 2021.
} 


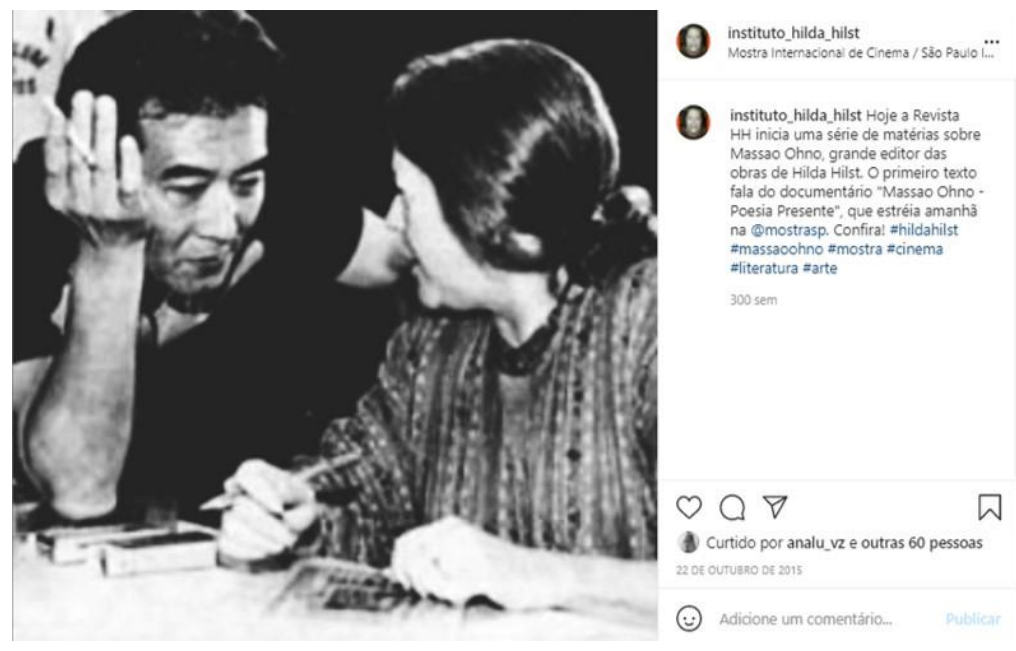

Figura 3 - Tela capturada do Instagram do IHH sobre a relação de Hilst e seu editor, tema do documentário Massao Ohno - Poesia Presente Fonte: @instituto_hilda_hilst ${ }^{31}$

Ainda no ano de 2015, o IHH publica a imagem da capa do livro A obscena senhora D, editada em 1982 por Ohno, acompanhada do texto que promete ao leitor mais informações sobre a relação entre a escritora e seu "editor mais fiel", onde lemos: “capa de 'A Obscena Senhora D' em edição de Massao Ohno. O 'japonês', como Hilda o chamava, foi seu editor mais fiel. Saiba mais sobre a relação dos dois na Revista HH!" ${ }^{32}$. Finaliza-se a mensagem com as hashtags \#hildahilst, \#massaoohno, \#literatura, a exemplo do que vemos na figura 4.
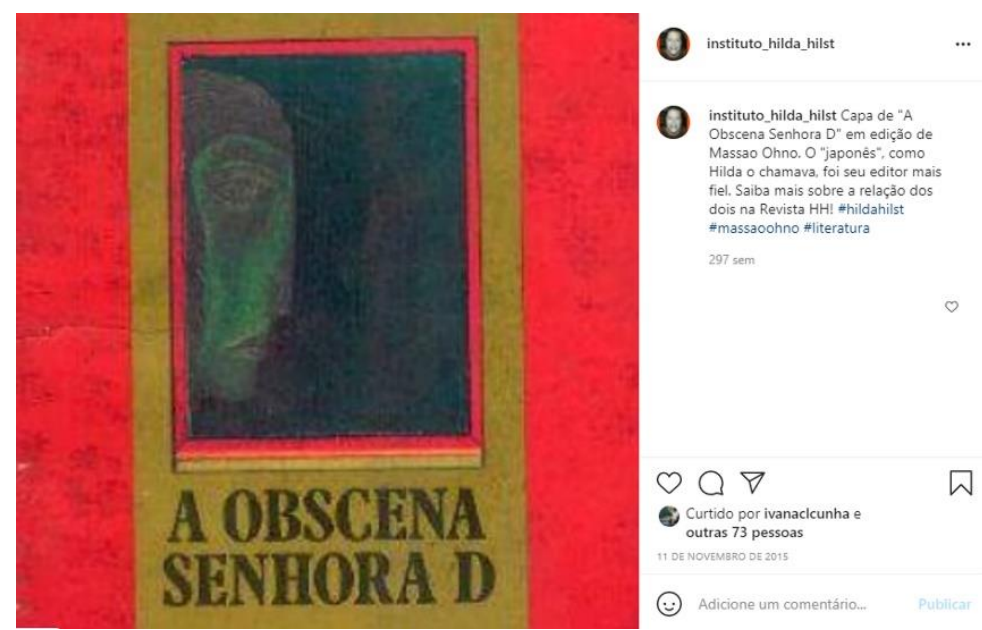

Figura 4 - Tela capturada do Instagram do IHH com a primeira capa de $A$ obscena senhora $D$, publicada em 1982 pelo selo independente Massao Ohno Editor

Fonte: @instituto_hilda_hilst ${ }^{33}$.

\footnotetext{
${ }^{31}$ Disponível em: https://www.instagram.com/p/9J4sJWJNc0/ Acesso em: jul. 2021.

${ }^{32}$ Disponível em: https://www.instagram.com/p/99N6oOJNQq/ Acesso em: jun. 2021.

${ }^{33}$ Disponível em: https://www.instagram.com/p/99N6oOJNQq/ Acesso em: jul. 2021.
} 
Também podemos observar a proposição de um Projeto de Memória Oral do IHH em parceria com o Itaú Cultural, em 2015, com o objetivo de "revitalizar e organizar o acervo de Hilda Hilst e de outros artistas e escritores dentro da Casa do Sol”34, como podemos ver na figura 5. Entre os participantes está a artista Shirley Stefanowski que trabalhou diretamente com Ohno, sendo responsável pela interlocução entre a escritora e o editor durante o processo de revisão e impressão gráfica das obras hilstianas.

\section{Memória Oral} Shirley Stefanowski trabalhou com Massao Ohno e participou da edição dos livros de Hilda Hilst

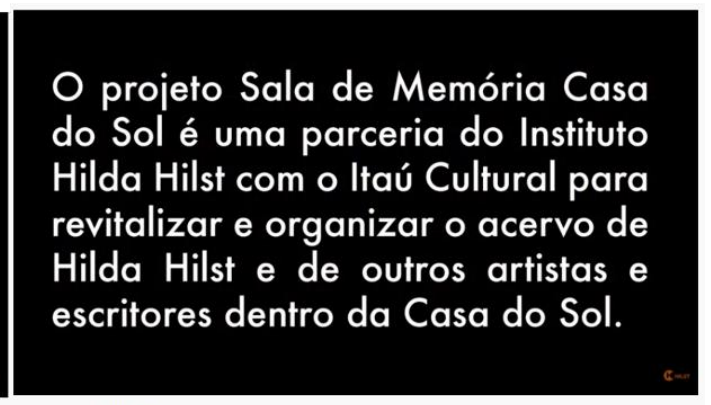

Memorria oral - Shirley III

Figura 5 - Telas capturadas do vídeo do Projeto Memória Oral com o depoimento de Shirley Stefanowski Fonte: @CuradoriaHilst ${ }^{35}$

No que diz respeito às práticas mnemônicas transversais do Instituto Hilda Hilst até aqui observadas, podemos inferir que os acervos hilstianos são compostos por testemunhos, fotografias, registros audiovisuais, entre outros. Em relação ao testemunho, o historiador Paul Ricoeur ${ }^{36}$ fundamenta que este dá à memória seu caráter declarativo, ou seja, por meio da linguagem narra-se um acontecimento de "forma bastante expressiva: “Eu estava lá”. Assim, por meio da oralidade, essa memória declarativa ainda conta com a potência viva do corpo (a voz, os gestos, as entonações). Desse modo, sugere o autor, o testemunho pode apoiar ou complementar os outros suportes físicos mnésicos, sendo muitas vezes, utilizado como fonte de proposições jurídicas ou históricas. No entanto, como Ricoeur alerta, o testemunho caracteriza-se também por fragilidades, incoerências, imperfeições, e, não menos, por simulações. Já do ponto epistemológico da memória, a transcrição do testemunho, ou seja, a passagem da narração para a escrita traduziria a memória declarada em arquivo e, consequentemente, em prova documental. Assim, Ricoeur define arquivo como o lugar físico e social que abriga o destino deste rastro documental. No entanto, como o arquivo está subordinado ao recorte narrativo, este deve ser objeto de questionamentos em relação à sua intenção veritativa ${ }^{37}$.

Já a pesquisadora e professora alemã Aleida Assmann ${ }^{38}$, em diálogo com seus estudos sobre teoria literária, antropologia e memória cultural, recupera a origem grega arché da palavra arquivo que se refere, simultaneamente, a início, origem, autoridade e escritório público. Nas palavras de Assmann, o arquivo existe graças aos sistemas de registro que permitem o seu armazenamento externo. Na condição de resíduo, o arquivo passa a ser também coletado, preservado

\footnotetext{
${ }^{34}$ Disponível em: https://youtu.be/W9TMmumyK0M Acesso em: jul. 2021.

${ }^{35}$ CuRAdORIA HILST. Disponível em: https://youtu.be/W9TMmumyK0M Acesso em: jul. 2021.

${ }^{36}$ Ricoeur, PAUl. A memória, a história, o esquecimento. Campinas: Editora Unicamp, 2007, p. 156.

${ }^{37}$ Ibidem.

${ }^{38}$ ASSMANN, ALEIDA. Espaços da recordação: formas e transformações da memória cultural. Campinas: Editora Unicamp, 2011, p. 368.
} 
e, posteriormente, enquadrado como fonte para historiadores. $\mathrm{Na}$ visão da professora, quando o arquivo se torna memória da economia e da administração, surge, então, o arquivo como testemunho do passado ${ }^{39}$.

Ainda pensando com Assmann, no que diz ao seu armazenamento, o arquivo também se submete a três características: conservação, seleção e acessibilidade. Nesse sentido, a autora, em consonância com os estudos de Jacques Derrida sobre a temática arquivística, destaca a ideia de que controlar o arquivo possibilita o controle da memória. Em suas palavras, graças às estruturas de legitimação do poder político, “o arquivo, antes de ser memória histórica, é memória da dominação" ${ }^{\# 0}$. Por outro lado, Assmann argumenta que os arquivos podem potencializar as memórias culturais futuras, o que não invalida a necessidade da crítica em relação à interpretação de seu status enquanto memória funcional ou de armazenamento. Nesse sentido, a apreensão dos arquivos se conduz por interesses sociopolíticos e midiáticos, que concorrem com o status quo das relações preestabelecidas, como explica a professora,

\begin{abstract}
Arquivos podem ser organizados tanto como metáforas funcionais quanto como memórias de armazenamento; no primeiro caso, eles contêm documentos e peças comprobatórias que asseguram a base legitimadora das relações de poder vigentes; no outro caso, revelam fontes potenciais que perfazem o fundamento do saber histórico de uma cultura. (...) pode-se ver nesse armazenador de saber um cemitério de dados, ou o material comprobatório de uma outra realidade, que concorre como o status quo das relações subsistentes ${ }^{41}$.
\end{abstract}

A pesquisadora alemã aponta que, com a tecnologia midiática em desenvolvimento, inaugura-se um "movimento fluido dos fluxos de dados digitais", o que culmina, em suas palavras, na passagem do "trans-histórico" para o "transitório" 42 graças à superfície na qual tudo se evidencia, exceto as alternâncias binárias entre 1 e 0 quando pensamos na consistência, vestígios e camadas dos espaços de recordação. Consequentemente, a memória cultural também passa a ser revisitada na dimensão espaçotemporal de acordo com as reflexões de Assmann.

Por outro lado, em diálogo com os seus estudos sobre memória e arquivo, a historiadora, socióloga e professora francesa Régine Robin ${ }^{43}$ afirma que há uma certa obsessão em relação à ideia de armazenamento de arquivos em dispositivos digitais, associada à "fantasia de tudo conservar" ${ }^{\text {"4 }}$, uma proposta bastante anterior ao surgimento da própria internet. $\mathrm{Na}$ visão da professora, o contexto virtual tanto pode potencializar esses espaços como destruí-los quando são invadidos por um hacker, por exemplo. Em suas palavras, "não se trata mais de um deslocamento da matéria, do óxido como na fita magnética, da prata como na película fotográfica, do grafite como faz o lápis no papel. A matéria digital codificada, hoje, é abstrata." ${ }^{\prime 4}$

Para a pesquisadora, a passagem de uma memória de arquivo analógica a uma memória de arquivo digital revela desafios singulares, uma vez que essa memória é continuamente "flutuante, de fluxo, de circuitos e redes, ela não é fixável, é móvel, e se opõe às memórias rígidas de armazenamento tradicionais" ${ }^{46}$. Assim, a autora sinaliza que os arquivos nas redes são

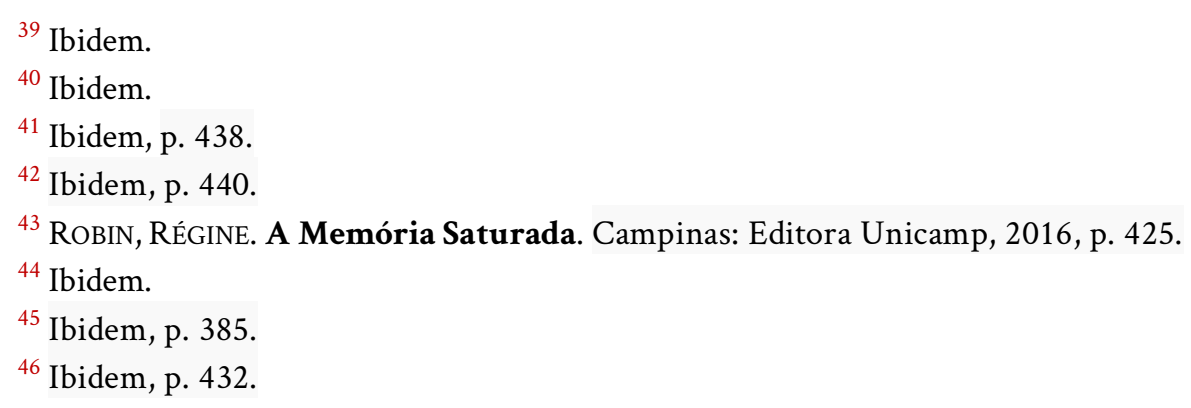


constituídos de fluxos contínuos de informações que chegam de todos os lugares ao contrário dos arquivos compreendidos em objetos, tais como, livros, dossiês, obras de arte, armazenados em lugares específicos como museus, arquivos ou bibliotecas. Nesse sentido, Robin alerta que "tudo se transformou em arquivo" ${ }^{47}$ na busca da conservação como uma forma de lidarmos com o "pesadelo do desaparecimento"48 o que, na visão da pesquisadora, pode nos levar a uma "fábrica de petrificação" ${ }^{\text {" }}$. No entanto, Robin, a exemplo de Assmann, aciona os estudos do Jacques Derrida para alertar que o arquivo não se define apenas pelo seu armazenamento, pois, muitas vezes, o arquivo acaba por se instalar no lugar onde há uma falta originária e estrutural de memória ${ }^{50}$.

Nesse sentido, a partir das contribuições de Ricoeur, Assmann e Robin, podemos reconhecer que as práticas mnemônicas e arquivísticas estão inseridas no contexto transitório, incompleto e fluído da ambiência digital. Em certa medida, podemos visualizar indícios ou rastros de uma gênese arquivística no que diz respeito à relação entre a escritora Hilda Hilst e o editor Massao Ohno graças à composição desses novos espaços ubíquos de memória, ainda que em camadas ou vestígios. Em outras palavras, testemunhos, fotografias, documentos revelam a convivência frutífera entre ambos na memória cultural no espaçotemporal virtual. No entanto, sob essa ótica, encontramos também desafios, a exemplo da frustração pela busca do armazenamento total em função das propriedades e das limitações do médium, como nos aponta Robin. Nesse sentido, o arquivamento de determinados nomes ou projetos em detrimento de outros revela a dimensão política da memória quando pensamos que os arquivos também podem ser objeto de controle e disputa como se refere Assmann.

Por outro lado, a exemplo do que apresentamos até aqui, graças ao caráter transitório e atemporal da fluidez desse médium, os rastros arquivísticos podem se reapresentar em um continuum memorialístico que se espraia em traços curatoriais, tema que apresentamos a seguir.

\section{Curadoria, memórias e teias midiáticas}

Em 2020, por conta do isolamento social imposto pela pandemia de Covid-19, as atividades culturais presenciais da Casa do Sol foram suspensas. Nesse ínterim, o Instituto Hilda Hilst cria o canal Curadoria Hilst na plataforma YouTube com uma programação on-line, com ampla divulgação nas redes sociais Facebook e Instagram. Dentre elas, destacamos: os Diários na Casa do Sol e a série Pílula Poética: poesia em movimento.

Nos episódios dos Diários da Casa do Sol, encontramos entrevistas e vídeos gravados que exibem ambientes, objetos, livros, fotografias e testemunhos de pessoas próximas à poeta. A série vem sendo conduzida pela artista plástica Olga Bilenky, que também era amiga da cronista e, atualmente, mora na Casa do Sol. Como podemos observar na figura 6, o episódio nº 31 dos Diários da Casa do Sol denominado A Catarse de ter convivido com Hilda Hilst e Massao Ohno ${ }^{51}$, traz novamente a participação da artista Shirley Stefanowski para falar sobre a relação com a escritora e "o grande mestre das artes editoriais e editor preferencial de Hilda ao longo da vida" ${ }^{2}$, como podemos ler no texto da publicação no Instagram: "Nos Diários da Casa do Sol desta

\footnotetext{
${ }^{47}$ Ibidem.

${ }^{48}$ Ibidem.

${ }^{49}$ Ibidem.

${ }^{50}$ Ibidem.

${ }^{51}$ Disponível em: https://youtu.be/eiZkew62c6s Acesso em: jul. 2021.

${ }^{52}$ Disponível em: https://www.instagram.com/p/CG0OywnHAVx/ Acesso em: jul. 2021.
} 
semana, Olga Bilenky recebe a amiga Shirley Stefanowski que, nos anos 1990, conviveu com Hilda Hilst e Massao Ohno, grande mestre das artes editoriais e editor preferencial de Hilda ao longo da vida" ${ }^{3}$.

Já a imagem é composta pela fotografia colorida da convidada, em destaque menor, sobreposta à imagem em preto e branco de Ohno e Hilst, a mesma utilizada em publicação de 2015, a exemplo da figura 3 que apresentamos anteriormente neste artigo. No entanto, entre as hashtags \#olgabilenky, \#hildahilst, \#casadosol, \#institutohildahilst, \#leiamulheres, \#curadoriahilst, \#diariosdequarentena, \#artesplasticas e \#pintura, não lemos o nome de Massao Ohno.

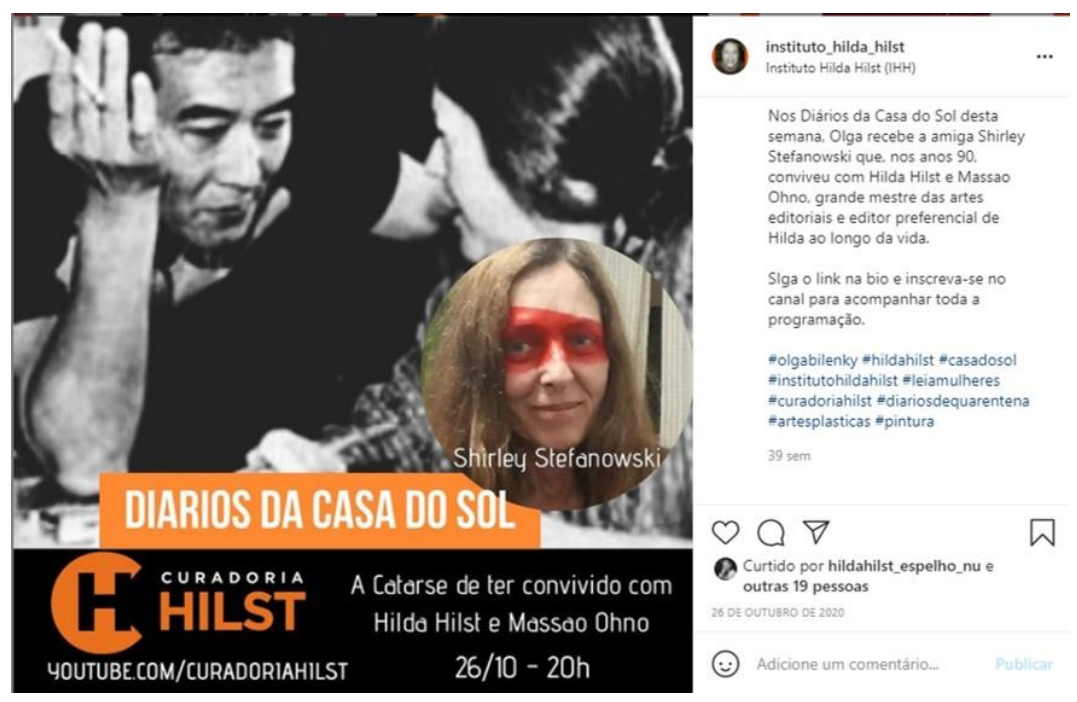

Figura 6 - Tela capturada do Instagram do IHH: Divulgação do episódio A Catarse de ter convivido com Hilda Hilst e Massao Ohno nos Diários da Casa do Sol

Fonte: @instituto_hilda_hilst ${ }^{54}$

Como ilustra a figura 7, a série Pílula Poética: poesia em movimento é uma exposição audiovisual dos poemas hilstianos. Em cada um dos vídeos dessa série no Curadoria Hilst, temos a participação de ilustradores, designers e da atriz Paula Santiago, que é quem faz a interpretação poética do texto. Na Pílula Poética no 39, no YouTube, Santiago faz a leitura de poema de abertura do livro Amavisse, cuja descrição no canal informa "Poema que abre 'Amavisse', publicado pela primeira vez em 1989 por Massao Ohno" ${ }^{55}$, fazendo referência ao editor independente.

\footnotetext{
${ }^{53}$ Disponível em: https://www.instagram.com/p/CG0OywnHAVx/ Acesso em: jul. 2021.

${ }^{54}$ Disponível em: https://www.instagram.com/p/CG0OywnHAVx/ Acesso em: 5 jul. 2021.

${ }^{55}$ Disponível em: https://youtu.be/ieQMFQCPpdk Acesso em: jul. 2021.
} 


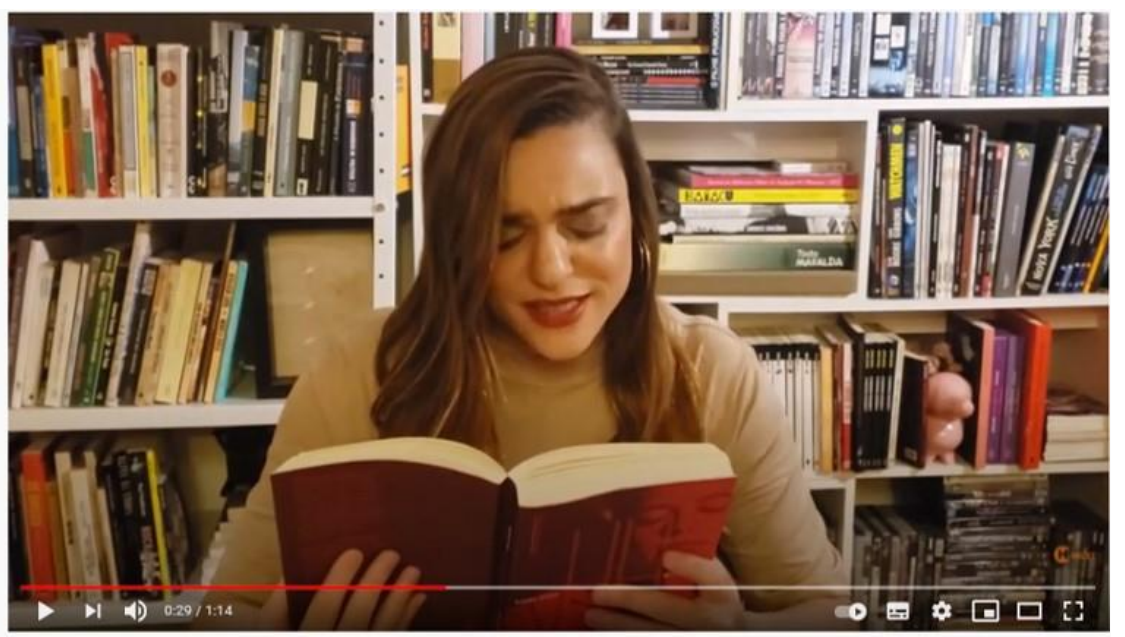

Pilula Poética de Hilda Hilst n॰39 - Amavisse

Figura 7 - Telas capturadas de Pílula Poética no 39, interpretada pela atriz Paula Santiago Fonte: @CuradoriaHilst ${ }^{56}$

Já em 2021, notamos a publicação da mensagem de lançamento de Amavisse e outros poemas ${ }^{57}$, editada pela Companhia das Letras, no Instagram do IHH, como mostra a figura 8. Nela, podemos observar que não há mais menção ao editor Massao Ohno como responsável pela primeira edição da obra hilstiana em 1989, como transcrevemos a seguir:

Amavisse acaba de ganhar uma edição belíssima pela @companhiadasletras, com capa de Elisa Von Randow (...) Em 1989, inconformada com a recepção de seus livros, Hilda Hilst afirmou que Amavisse marcava sua despedida: "Não vou publicar mais nada, porque considerei um desaforo o silêncio". Mais tarde, o volume se consagraria como um dos títulos mais celebrados de sua obra e seria incorporado à coletânea Do desejo, em 1992. A trajetória de Hilda na poesia se encerraria de fato poucos anos depois, em 1995. Este volume inclui a produção final da poeta: Amavisse, Via espessa, Via vazia, Alcoólicas, Do desejo, Da noite e Cantares do sem nome e de partidas. Em tom metafísico, os versos abordam a passagem do tempo, o fim do amor, os planos que não se concretizam, as barcas afundadas, a proximidade da morte: "Há de viver na paisagem da mente// Como a distância habita em certos pássaros/ Como o poeta habita nas ardências" ${ }^{\text {"5 }}$

\footnotetext{
${ }^{56}$ Disponível em: https://youtu.be/ieQMFQCPpdk Acesso em: jul. 2021.

${ }^{57}$ Hilst, HiLdA. Amavisse e outros poemas. São Paulo: Companhia das Letras, 2021.

${ }^{58}$ Disponível em: https://www.instagram.com/p/CRR9Z1Xn8k9/ Acesso em: 5 jul. 2021.
} 


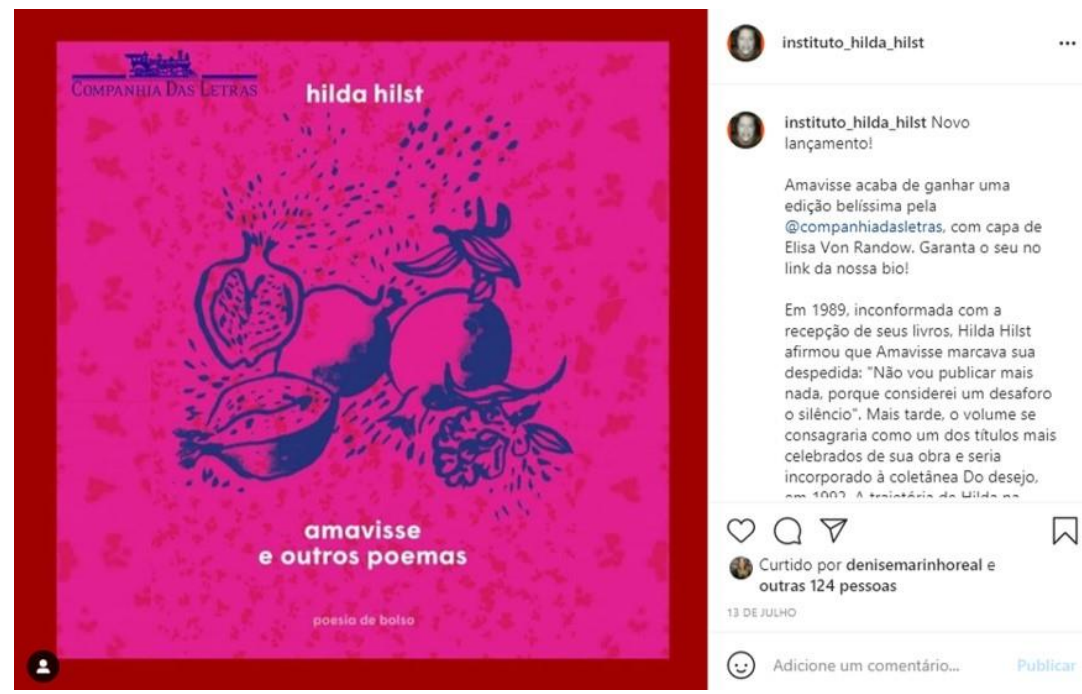

Figura 8 - Tela capturada do Instagram do IHH sobre o lançamento de Amavisse e outros poemas pela editora Companhia das Letras Fonte: @instituto_hilda_hilst ${ }^{59}$

Em suas reflexões artísticas, o curador suíço Hans Ulrich Obrist ${ }^{60}$ traz o dilema arquivístico também no que diz respeito às exposições. Na visão do pesquisador, a obsessão pelo armazenamento leva à dificuldade de encontrar um lugar para colocar a completude dos arquivos. No entanto, Obrist acredita que, no século XXI, as contribuições artísticas que vão perdurar não são, necessariamente, aquelas construídas em estruturas físicas. Nas palavras do curador, podemos ter repositórios de ideias e feitos, e não apenas de objetos ${ }^{61}$.

Obrist conta que, desde 1990, coleta informações sobre exemplos incomuns de arte, ou seja, projetos não realizados. Para ele, são reservatórios de ideias artísticas: projetos esquecidos, projetos direta ou indiretamente censurados, projetos incompreendidos, projetos oprimidos, projetos perdidos, projetos irrealizáveis. O curador entende que as atualizações de projetos não realizados ou fracassados fazem parte desse repositório de possibilidades outras, uma vez que, normalmente, não chegamos a conhecer os trabalhos descontinuados. Nesse sentido, para Obrist, a curadoria está mais próxima da ideia de um projeto inacabado e, como tal, é uma prática que nos possibilita criar o futur ${ }^{62}$.

Já o professor, tradutor e crítico literário Márcio Seligmann-Silva ${ }^{63}$ afirma que, entre o mundo sensível e o conceitual, localiza-se a imaginação que proporciona o funcionamento da arte da memória como tradutor de histórias em imagens e, como tais, em falas ou textos. Nesse sentido, a arte da memória revela a transformação da história em uma escrita imagética com posterior legibilidade, o que permanece como ponto central na contemporaneidade. De acordo com o crítico literário, essa tendência intensifica-se com movimentos que circundam as questões anticolonialistas, das mulheres e das minorias. Assim, constitui-se uma cultura da memória "como resistência ao esquecimento oficial" e uma "cultura da amnésia, do apagamento do passado, o que caracteriza nossa sociedade globalizada pós-industrial” ${ }^{64}$.

\footnotetext{
${ }^{59}$ Disponível em: https://www.instagram.com/p/CRR9Z1Xn8k9/ Acesso em: 5 jul. 2021.

${ }^{60}$ ObRIST, Hans. Caminhos da Curadoria. Rio de Janeiro: Cobogó, 2014.

${ }^{61}$ Ibidem.

${ }^{62}$ Ibidem.

${ }^{63}$ SELIGMANN-Silva, MÁRCiO. “A escritura da memória: mostrar palavras e narrar imagens”. Remate de Males, Campinas, jan./jul., n. 26, 2006.

${ }^{64}$ Ibidem, p. 39.
} 
A partir das reflexões de Obrist e Seligmann-Silva, podemos inferir que as práticas mnemônicas transversais dos acervos hilstianos estão compreendidas nos projetos curatoriais do Instituto Hilda Hilst que busca, por um lado, inserir a obra da escritora na tessitura midiática digital, principalmente, quando pensamos na programação do canal Curadoria Hilst na plataforma YouTube e sua divulgação no Instagram, tendo em vista o cronograma de lançamento dos títulos hilstianos em novas edições da Companhia das Letras, a partir da comemoração aos 90 anos de nascimento de Hilda Hilst em 2020.

Ainda que sejam reconhecidas como estratégias do mercado editorial, essas práticas inserem as obras de Hilst na esfera comunicacional, midiática e editorial, de modo, talvez, a fomentar novos leitores, como ansiava a poeta. Nesse sentido, podemos inferir que Massao Ohno tinha razão: os livros que ele editou artisticamente germinam a poética e a prosa hilstianas em temporalidades outras, acionando a memória cultural como vimos com Assmann. Por outro lado, pensando com Obrist, o projeto não realizado por Ohno de transformar as edições de Hilst em livros comerciais ganha uma nova oportunidade de ser factível graças à cultura da memória e à cultura da amnésia a que se refere Seligmann-Silva quando percebemos a inserção de novos rastros nesses fluxos, a exemplo das hashtags \#leiamulheres, \#curadoriahilst e \#diariosdaquarentena. Sob essa perspectiva, podemos dizer que se trata de uma curadoria ritualizada de memórias ${ }^{65}$ quando percebemos que essas práticas buscam projetar um futuro memorialístico nas contínuas reescrituras dos rastros arquivísticos digitais.

\section{Considerações Finais}

Neste artigo, apresentamos os rastros arquivísticos digitais que passam a compor as práticas mnemônicas transversais do Instituto Hilda Hilst no continuum dos fluxos digitais, corroborando a permanência tanto da escritora quanto de seu editor na tessitura da memória cultural e midiática. Dessa forma, o fazer-memória permite a reescritura de um projeto inacabado sob outros enquadramentos.

Por outro lado, ao observamos esses rastros, podemos inferir que o ato de fazer-memória de Hilst e de Ohno implica também o seu oposto: fazer-esquecimento, compreendido como um desafio arquivístico na ambiência virtual.

Ainda que não seja objeto de nossa discussão esgotar essa temática, podemos inferir que, ao inserirmos os acervos de Hilst e de Ohno em espaços ubíquos virtuais, promovemos o surgimento de outras narrativas sobre escritores, editores, leitores e livros. Assim, talvez, os nomes de Hilst e Ohno possam fomentar o interesse pelas artes literárias e gráficas nos fluxos digitais, assim como a dimensão memorável da relação poética e visceral que viveram.

\footnotetext{
${ }^{65}$ BACEGA, DÉBORA R.; Nunes, MôniCA R.F. "Memória, ritual e consumo no clube de livros TAG Experiências Literárias”. Animus Revista Interamericana de Comunicação Midiática, v.19, no 41, 2020. Disponível em: https://periodicos.ufsm.br/animus/article/view/44516/pdf Acesso em: 5 jul. 2021.
} 


\section{Referências bibliográficas}

ASSMAnN, AleidA. Espaços da recordação: formas e transformações da memória cultural. Campinas: Editora Unicamp, 2011.

BACEGA, DÉbORA R.; Nunes, MôNICA R.F. "Memória, ritual e consumo no clube de livros TAG Experiências Literárias”. Animus Revista Interamericana de Comunicação Midiática, v.19, no 41, 2020. Disponível em: https://periodicos.ufsm.br/animus/article/view/44516/pdf Acesso em: 5 jul. 2021.

DINIZ, CRISTIANO. (org.). Fico besta quando me entendem: entrevistas com Hilda Hilst. São Paulo: Editora Globo, 2013. FueNTES, DANIEL. A gestão de um legado. Cult. São Paulo: Editora Bregantini, n. 233, p. 38-41, abr. 2018.

HILST, HILDA. Trovas de muito amor para um amado senhor. São Paulo: Massao Ohno, 1961.

HILST, HILDA. Sete cantos do poeta para o anjo. São Paulo: Massao Ohno 1962.

HiLst, Hilda. Da Morte. Odes mínimas. São Paulo: Massao Ohno, Roswitha Kempf, 1980.

HILST, HILDA. Cantares de perda e predileção. São Paulo: Massao Ohno/M. Lídia Pires e Albuquerque Editores,1980.

HiLST, HILDA. A obscena senhora D. São Paulo: Massao Ohno, 1982.

HILST, HILDA. Sobre a tua grande face. São Paulo: Massao Ohno, 1986.

HiLST, HildA. Amavisse. São Paulo: Massao Ohno, 1989.

HILST, HILDA. O caderno rosa de Lori Lamby. São Paulo: Massao Ohno, 1990.

HILst, HildA. Bufólicas. São Paulo: Massao Ohno, 1992.

Hilst, HiLdA. Do amor. São Paulo: Massao Ohno, 1999.

HILST, HILDA. Amavisse e outros poemas. São Paulo: Companhia das Letras, 2021.

Medeiros, Gutemberg. "Massao Ohno, Hilda Hilst e os três triplos”. Jornal da USP on-line. Disponível em: https://jornal.usp.br/artigos/massao-ohno-hilda-hilst-e-tres-triplos/ Acesso em: 15 jun. 2021.

OBRIST, HANS. Caminhos da Curadoria. Rio de Janeiro: Cobogó, 2014.

PÉCORA, AlCIR. "Livro sobre Massao Ohno teve pesquisa criteriosa mas falta biografia”. Folha S. Paulo on-line. Disponível em: https://www1.folha.uol.com.br/ilustrada/2020/04/livro-sobre-massao-ohno-teve-pesquisa-criteriosa-mas-faltabiografia.shtml?origin=folha Acesso em: 15 jun. 2021.

Prestes, PaOla. Massao Ohno - Poesia Presente. Documentário, 90 min, Brasil, 2015.

Ricoeur, Paul. A memória, a história, o esquecimento. Campinas: Editora Unicamp, 2007.

Robin, RÉGINE. A Memória Saturada. Campinas: Editora Unicamp, 2016.

SELIGMANN-SILVA,MÁRCIO. A escritura da memória: mostrar palavrase narrar imagens. Remate de Males, Campinas,jan.jul,,n. $26,2006$.

SILVA, José ARMAndo P. Massao Ohno, editor. São Paulo: Ateliê Editorial, 2020.

Recebido em: 30/06/2021 